\title{
Early Complications After Penetrating Keratoplasty
}

\author{
Moulaye A Haidara and Bennie $\mathrm{H}$ Jeng \\ Department of Ophthalmology and Visual Sciences, University of Maryland School of Medicine, Maryland, US
}

DOI: https://doi.org/10.17925/USOR.2016.09.02.88

A Ithough endothelial keratoplasty has gained increasing popularity over the last decade in the US, penetrating keratoplasty (PK) continues to have a role in the treatment of corneal diseases. This is especially true in developing nations where endothelial keratoplasty has not been popularized, and where isolated endothelial disease is much less common. In these situations, PK is still indicated. As with any surgical procedure, PK carries with it complications that can threaten the success of the procedure, including wound-related issues, ocular surface disease, infections, and suture-related complications. This article will review the various aspects of early complications after PK occurring within the first 2 months of surgery, along with management techniques. A review of the current literature was performed via a Medline search using the keywords "penetrating keratoplasty," "complications," "cornea," and "transplant." All articles containing descriptions of early postoperative complications after PK were reviewed, and the more commonly encountered complications are discussed in this article.

\section{Keywords}

Penetrating keratoplasty, complications, cornea, transplant

Disclosure: Moulaye A Haidara and Bennie H Jeng have nothing to declare in relation to this article. No funding was received for the publication of this article. This study involves a review of the literature and did not involve any studies with human or animal subjects performed by any of the authors.

open Access: This article is published under the Creative Commons Attribution Noncommercial License, which permits any noncommercial use, distribution, adaptation, and reproduction provided the original author(s) and source are given appropriate credit.

Received: July 13, 2016

Accepted: September 7, 2016

Citation: US Ophthalmic Review, 2016;9(2):88-91

Corresponding Author: Bennie H Jeng, Department of Ophthalmology and Visual Sciences, 419 West Redwood St, Suite 470, Baltimore, Maryland 21201, US. E: bjeng@som.umaryland.edu
The number of cases of endothelial keratoplasty (EK) performed in the US has surpassed that of penetrating keratoplasty (PK) as of 2012, ${ }^{1}$ but PK is still a frequently performed procedure. As such, corneal transplant surgeons must still be able to recognize and treat the various complications that can be encountered after PK, ranging from anterior segment issues to posterior segment complications. This article will examine some of the major complications encountered in the earlier stages after the procedure, along with management techniques whenever appropriate.

\section{Complications related to wound closure}

One of the critical steps in PK is wound closure, and the adequateness of the sutures will determine not only postoperative astigmatism (which will not be discussed here), but also the presence of wound leaks, or even graft failure. In the early postoperative period, the intraocular pressure (IOP) is closely monitored, and a low pressure should raise concerns for a possible wound leak. Even though other causes of low IOP are possible in the early postoperative period (as will be discussed later in this article), wound leaks should be considered first. The presence of a shallow anterior chamber should also raise suspicion for a wound leak. The diagnostic test of choice is a Seidel test. This is performed by placing a fluorescein strip over the wound areas: in the presence of leakage of fluid from the wound or suture track, the orange dye will be diluted and turn green. The amount of leakage from different areas can thus be observed. ${ }^{2}$ Other modalities are sometimes also employed to diagnose occult wound leaks, such as ultrasound biomicroscopy as was described by sicco et al. ${ }^{3}$

The treatment modality will depend on the type and extent of leakage present. In the presence of a flat anterior chamber, the wound leak should be urgently closed in the operating room. ${ }^{2}$ The presence of iris prolapse, even in the absence of a flat chamber, which will increase the risk for infection, should also be immediately surgically repaired in the operating room. ${ }^{4}$ The urgency is to avoid contamination that could lead to infection, as well as to avoid prolonged contact between the corneal endothelium and other structures, which may ultimately lead to endothelial cell death and graft failure. ${ }^{5}$

In the absence of a flat anterior chamber, other modalities may be considered based on the extent of the leakage. A pressure patch, or soft bandage contact lens, may be useful in the presence of a small leak. Lowering the IOP with aqueous suppressants, or rotation of a continuous suture if used instead of interrupted sutures, may all help in decreasing the leakage and allow the wound leak to close on its own. However, when the above measures fail to control the leak, in order to avoid a persistent fistula, infections, or epithelial downgrowth, surgical repair is highly recommended 
within a few days postoperatively. There is no clear time frame as to when the leak should be surgically closed, but there are reports of epithelial downgrowth if the leak is not promptly managed.1,2, Loose or broken sutures should be replaced in the presence of leaks or wound dehiscence. Iris prolapse should be surgically repaired. If the prolapse occurred with 24 hours, the tissue should be replaced using a blunt spatula and viscoelastic agents. If the prolapsed tissue is over 24-hours old, with signs of necrosis, then it should be excised. The method of repair will depend on the wound characteristics., ${ }^{3,7}$ Beside surgical closure with sutures, tissue adhesives can also be considered. ${ }^{4.5}$

The overall success of wound closure starts with prevention of leaks with good wound construction during the initial surgery. Those details are beyond the scope of this review. Newer techniques of wound construction, such as the use of femtosecond laser, have also lead to a decrease in wound leaks. ${ }^{6-8}$

\section{Complications related to epithelial healing}

One of the issues frequently encountered after PK is the persistence of epithelial defects. ${ }^{9,10}$ Proper re-epithelialization and the presence of an intact epithelium is important for visual acuity, graft survival, prevention of infectious keratitis, wound integrity, and prevention of corneal melt.9,10 The presence of certain risk factors also potentiates the epithelial defects. Hence, aggressive prevention and treatment of prior ocular surface diseases are imperative for better visual outcomes and for preventing graft failure..$^{11,12}$ It is important to not dismiss epithelial defects as just being failure of re-epithelialization, as an infectious etiology should always be considered, especially in hosts who have had previous herpetic keratitis. ${ }^{11-14}$

As the re-epithelialization process emanates from the graft recipient, a healthy ocular surface will help in proper epithelial healing. However, other factors, such as age and poor donor tissue health, may increase the risk for epithelial defects. ${ }^{9,15}$ It is therefore imperative to consider the donor tissue at the time of transplantation. Death to preservation time, storage time, storage media, and health of the donor epithelium should be carefully assessed, especially when a persistent epithelial defect is anticipated in a recipient with ocular surface diseases. ${ }^{16-18}$

The presence of infectious keratitis can also predispose to persistent epithelial defects. In PK for viral keratitis, such as from herpes simplex virus or varicella zoster virus, the incidence was close to $50 \%$ in some series, with the incidence approaching 100\% when PK was carried out during an active episode. ${ }^{11,13,19-21}$ Therefore, when possible, proper treatment of infections and ocular surface diseases prior to PK is indicated.

It was postulated that epithelial removal improved graft survival by reducing the histocompatibility antigen load on the donor tissue. ${ }^{15}$ However, this practice was abandoned when it was shown that removal of donor epithelium did not affect graft rejection or failure. . $5,16^{16}$ Subsequently, preservation of donor epithelium is advocated, especially in patients at high risk for persistent epithelial defects. The healthier the donor epithelium for those patients, the shorter the time for re-epithelialization, as has been shown in patients with bullous keratopathy who underwent PK. ${ }^{15}$ Various methods should be used to keep donor tissue moist throughout the procedure. Sodium hyaluronate, as opposed to balanced saline solution, can also be used to hydrate the cornea, as this has been shown to result in improved epithelial integrity 1 week after the procedure..$^{10,16}$

Other methods to consider in treatment and prevention of postoperative epithelial defects are tarsorrhaphy, pressure patching, bandage contact lens, collagen shields, and amniotic membrane.9,10,17 Postoperative medications should also be modified to lessen epithelial toxicity, as appropriate. Other modalities, such as epidermal growth factor, fibronectin, and others have been studied, with variable results. ${ }^{18,19}$ The presence of active infections should always be assessed and treated accordingly.

\section{Filamentary keratitis}

Filamentary keratitis (FK) is associated with multiple ocular surface diseases. Current evidence indicates that aqueous deficiency dry eye is the most common ocular condition associated with FK. ${ }^{20}$ Studies have also shown that FK was present in up to $27 \%$ of patients with keratoconus who underwent PK. ${ }^{21}$

Various treatment modalities for FK have been described. However, hypotonic artificial tears, as well as careful removal of the filaments with a forceps, and acetylcysteine can be helpful. 20,22-25 Punctal occlusion, blepharoplasty, botulinum toxin for temporary tarsorrhaphy, and soft bandage contact lens may also be used depending on the cause of the FK. ${ }^{26-28}$

\section{Suture-related complications}

Suture-related complications range from symptoms of foreign body sensation, pain, epiphora, photophobia, to findings of FK, infections, and even increased risk for rejection from stimulation of local inflammation. ${ }^{4,29-35}$ Infections are a concern with suture exposure, and suture abscess, when it occurs, can lead to devastating outcomes. The progression and outcome depends on the causative organisms and proper management. Suture-related immune infiltrates are another complication that can occur in the early postoperative period, and distinction between this process and infectious infiltrates is paramount for proper treatment. The immune response has been postulated to be from the suture material, or from particles that adhere to the sutures during the surgical procedure, such as talc from gloves. ${ }^{36,37}$ Immune infiltrates are usually seen along multiple suture tracks, along the host side of the graft-host interface, and have no overlying epithelial defect compared with infectious infiltrates. ${ }^{38}$

The treatment of suture-related infections begins with removal and culture of the suture. Running sutures pose a particular challenge as premature removal of the suture prior to proper would healing can lead to wound dehiscence. The initial treatment of suture-related infections is broad-spectrum fortified antibiotics, and once organisms are isolated and sensitivities are available, a step-down approach is followed. Topical steroids should be temporally stopped, and can be substituted with systemic corticosteroids especially if a rejection episode is imminent. Steroids can be resumed once the infection is subsiding. ${ }^{39,40}$ On the other hand, suture-related immune infiltrates should be treated with an increased corticosteroid regimen. Systemic steroids or other immunosuppressants can also be used..$^{41,42}$ Once the infiltrates subside, a slow taper is initiated based on clinical response. ${ }^{43}$

An interesting finding consisting of white dots in the donor corneal epithelium adjacent to the sutures has been described by Kaye. ${ }^{44}$ These lesions do not stain with fluorescein, are not related to drugs, 
and are not associated with infections or rejection. They usually appear from 1 week to 7 weeks after initial graft procedure, and disappear over 1 month. The patient is asymptomatic, and no change in management is needed. ${ }^{44}$

\section{Intraocular pressure-related complications}

Elevated IOP after PK is a major concern in the early postoperative period. An electronic tonometer is recommended given the inaccuracy of the Goldmann applanation in the presence of corneal edema and surface irregularities. ${ }^{45}$ Elevated IOP can lead to irreversible endothelial cell damage. ${ }^{45,46}$ Different speculations exist as to the high incidence of elevated postoperative pressures, with different suggestions for management. Prompt treatment is the rule to avoid worse visual outcomes or graft failure.

Pre-existing glaucoma, retained viscoelastic material, intraocular inflammation, anterior synechia, and large graft size have all been implicated in postoperative elevated IOP. ${ }^{47,48}$ When elevated IOP is expected, the use of topical beta-blockers, topical alpha-2 agonists, or topical carbonic anhydrase inhibitors can be used at the end of the procedure. Prostaglandin analogs and miotic agents should be avoided since they can exacerbate inflammation. ${ }^{14,36,45}$ Topical agents should also be used sparsely to avoid secondary epitheliopathy. Systemic agents may be used in the appropriate setting. If elevated IOP continues to be an issue, then surgical approaches may be considered, such as glaucoma filtration surgeries with or without the use of metabolites such as mitomycin C, tube shunts, or cyclocryotherapy. $45,46,49,50$

\section{Anterior segment inflammation-related complications}

Proper control of postoperative inflammation is critical to good outcomes after PK. A major concern is the fibrin formation with formation of membranes that can lead to pupillary block glaucoma, as well as damage to the endothelium leading to graft failure. ${ }^{51}$ Other concerns are anterior synechia formation, which can lead to angle closure glaucoma, leading to optic nerve and endothelial cell damage. Therefore proper management is needed to avoid synechia formation. Another complication, though rare, is postoperative hyphema, especially in the setting of synechiolysis, and iridectomy.

Topical corticosteroids are usually effective in controlling postoperative inflammation. Mydriatics should also be considered for pain, and they also prevent lens-iris synechia formation. With the formation of fibrin, the use of tissue plasminogen activator (TPA) may be needed. ${ }^{51}$ The smallest effective TPA dose should be used. ${ }^{52,53}$

In cases where anterior synechia formation is a concern, existing anterior synechia should be released by blunt and sharp dissection to arrive at a complete synechiolysis. Proper wound apposition, surgical iridoplasty/ iridectomies, and use of mydriatics may prevent or lessen the risk for synechia formation. ${ }^{54,55}$ However, the use of mydriatics should be used judiciously, as wide dilations can lead to iris adhesion to the wound, or lead to permanent dilated pupils. ${ }^{56}$ As mentioned previously, control of inflammation is essential for prevention of synechia formation. Once anterior synechia are observed postoperatively, close observation is adequate for small adhesions; however, synechia with more than 180 degrees of angle involvement, and with evidence of early graft rejection/failure, may necessitate surgical correction. ${ }^{56,57}$
Another complication that can lead to anterior synechia formation is pupillary block. A flat or shallow anterior chamber usually accompanies pupillary block in the absence of wound leak. It is usually associated with elevated IOP; however, low or normal pressures may also be seen. ${ }^{58}$ Posterior synechia or vitreous present in the iridectomy sites help elucidate the diagnosis. Treatment consists of use of cycloplegic and mydriatic drops to dilate the pupil. In the presence of elevated IOP, various drops can be used. In the presence of inflammation, topical or systemic corticosteroids should be used as well. Peripheral iridectomies should also be considered with failure of medical management. 59,60 Lastly, postoperative hyphema is usually managed conservatively, with use of topical IOP-lowering drops. Mydriatic agents and topical corticosteroids are also recommended to prevent posterior synechiae formation and inflammation, respectively. ${ }^{51}$ If the hyphema fails to clear spontaneously, and there are concerns for synechial formation, corneal bloodstaining, or persistent elevated IOPS, surgical management may be required: clot irrigation with trabeculectomy, hyphema aspiration with vitrectomy instruments, or other surgical methods can be used. ${ }^{51}$

\section{Choroidal detachment and hemorrhage-related complications}

Choroidal detachments, usually due to uveal effusion or hypotony, are detected by ophthalmoscopy or B-scan ultrasound when the view is not clear. They present as domed shape elevations restricted by the vortex veins. A wound leak must be ruled out. Another complication that can occur is a choroidal hemorrhage, which is usually accompanied by a sudden onset of pain and change in vision. Many risk factors have been postulated, including age, cardiovascular disease, hypertension, and glaucoma. ${ }^{61,62}$

Since choroidal detachments can extend to the scleral spur and cause anterior displacement of the iris leading to angle closure and anterior synechia formation, adequate treatment is warranted. In the case of a wound leak, proper repair is indicated. Otherwise, postoperative choroidal detachments are self-limiting. If, however, the detachment persists for over 3 days, with evidence of angle closure, pupillary block, or other related complications, then surgical drainage is indicated, with reformation of the anterior chamber. ${ }^{63}$ On the other hand, if a choroidal hemorrhage occurs, close follow up is indicated, with possible surgical drainage. ${ }^{62,64,65}$

\section{Complications related to infections}

Contamination of the surgical field, donor graft, or incomplete excision of infected host tissue can lead to infectious keratitis. ${ }^{63}$ Other risk factors for bacterial or fungal keratitis include persistent epithelial defects, contact lens usage, suture-related complications, steroid use, and ocular surface disease.66,67

In the event of an early postoperative infectious keratitis, gram stain and cultures should be obtained. Treatment with broad-spectrum antibiotics should be initiated promptly until sensitivities are available. In case of extensive graft involvement, a re-graft should be performed to avoid endophthalmitis. ${ }^{68}$

\section{Primary graft failure}

Even with the most adequate preoperative evaluations and anticipation of various complications, sometimes a graft does not survive. Primary graft failure is a dreaded outcome of PK, which may result from unhealthy donor tissue, prolonged donor tissue preservation time, or trauma during surgery. It is also thought that decreased aqueous formation 
that can occur after PK may play a role since endothelial cells are not getting enough micronutrients in such situations.69,00,71 Even though donor age was thought to play a role in donor failure, recent data from the Cornea Donor Study found no statistically significant difference in the incidence of primary donor failure with tissue from donors younger than 66 years old compared with those between 66 and 75 years old. ${ }^{72,73}$ Primary graft failure presents as persistent corneal edema immediately after the procedure. ${ }^{74,75}$ In the event of graft failure, re-grafting is the next step in management.

\section{Conclusion}

Although PK is slowing being replaced by lamellar keratoplasty in the US, it is still the only treatment option in many instances; in most parts of the world, this is still the corneal transplant procedure of choice. While newer methods are available in graft sizing/rim configurations with the femtosecond lasers, complications are still bound to happen. A familiarity with possible complications and knowledge of proper management techniques are always be needed to assure the best outcomes for the patient.
1. Eye Bank Association of America, 2015 Eye Banking Statistical Report. Available at: www.restoresight.org/wp-content/ uploads/2016/03/2015-Statistical-Report.pdf. Accessed July 13, 2016.

2. Ma JF, Rapuano CJ, Hammersmith KM, et al., Outcomes of Wound Dehiscence Post-Penetrating Keratoplasty, Cornea 2016;35:778-83.

3. Sicco thoe Schwartzenberg GW, Pavlin CJ, Occult wound leak diagnosed by ultrasound biomicroscopy in patients with postoperative hypotony, I Cataract Refract Surg, 2001:27:549-54.

4. Das S, Whiting M, Taylor HR, Corneal wound dehiscence after penetrating keratoplasty, Cornea, 2007;26:526-9.

5. Moorthy S, Graue E, Jhanji V, et al., Microbial keratitis after penetrating keratoplasty: impact of sutures, Am J Ophthalmol 2011;152:189-94 e182.

6. Meyer JJ, McGhee $\mathrm{CN}$, Incidence, severity and outcomes of traumatic wound dehiscence following penetrating and deep anterior lamellar keratoplasty, Br J Ophthalmol, 2016 [Epub ahead of print]

7. Gunasekaran S, Sharma N, Titiyal JS, Management of traumatic wound dehiscence of a functional graft 34 years after penetrating keratoplasty, BMJ Case Rep, 2014; doi:10.1136/bcr-2014-205903.

8. Foroutan A, Tabatabaei SA, Behrouz MJ, et al., Spontaneous wound dehiscence after penetrating keratoplasty, Int Ophthalmol, 2014:7:905-8.

9. Ricci F, Missiroli F, Ciotti M, et al., Persistent epithelial defect after penetrating keratoplasty caused by adenoviral infectious keratitis, NeW Microbiol, 2010;33:171-4

10. Fu Y, Liu J, Tseng SC, Ocular surface deficits contributing to persistent epithelial defect after penetrating keratoplasty, Cornea, 2012;31:723-9.

11. Jansen AF, Rijneveld WJ, Remeijer $L$, et al., Five-year follow-up on the effect of oral acyclovir after penetrating keratoplasty for herpetic keratitis, cornea, 2009:28:843-5.

12. Sterk CC, Jager MJ, Swart-vd Berg M, Recurrent herpetic keratitis in penetrating keratoplasty, Doc Ophthalmol, 1995;90:29-33.

13. Borderie VM, Meritet JF, Chaumeil C, et al., Culture-proven herpetic keratitis after penetrating keratoplasty in patients with no previous history of herpes disease, Cornea, 2004;23:118-24.

14. Dunn SP, Gal RL, Kollman C, et al., Corneal graft rejection 10 years after penetrating keratoplasty in the cornea donor study, Cornea 2014:33:1003-9.

15. Meyer RF, Bobb KC, Corneal epithelium in penetrating keratoplasty, Am J Ophthalmol, 1980;90:142-7.

16. Kim T, Palay DA, Lynn M, Donor factors associated with epithelia defects after penetrating keratoplasty, Cornea, 1996;15:451-6.

17. Katzman $L R$, Jeng $B H$, Management strategies for persistent epithelial defects of the cornea, Saudi $\rfloor$ Ophthalmol, 2014:28:168-72.

18. Nishida T, The role of fibronectin in corneal wound healing explored by a physician-scientist, Jpn J Ophthalmol, 2012;56:417-31.

19. Sugioka K, Yoshida K, Kodama A, et al., Connective tissue growth factor cooperates with fibronectin in enhancing attachment and migration of corneal epithelial cells, Tohoku J Exp Med, 2010:222:45-50

20. Albietz J, Sanfilippo P, Troutbeck R, Lenton LM, Management of filamentary keratitis associated with aqueous-deficient dry eye, Optom Vis Sci, 2003;80:420-30

21. Rotkis WM, Chandler JW, Forstot SL, Filamentary keratitis following penetrating keratoplasty, Ophthalmology, 1982;89:946-49.

22. Perry HD, Doshi-Carnevale S, Donnenfeld ED, Kornstein HS, Topical cyclosporine A $0.5 \%$ as a possible new treatment for superior limbic keratoconiunctivitis, Ophthalmology 2003:110:1578-81.

23. Grinbaum A, Yassur I, Avni I, The beneficial effect of diclofenac sodium in the treatment of filamentary keratitis, Arch Ophthalmol, 2001;119:926-7.

24. Kakizaki H, Zako M, Mito H, Iwaki M, Filamentary keratitis mproved by blepharoptosis surgery: two cases, Acta Ophthalmol Scand, 2003;81:669-71.

25. Avisar R, Robinson A, Appel I, et al., Diclofenac sodium, $0.1 \%$ voltaren Ophtha), versus sodium chloride, $5 \%$ in the treatment of filamentary keratitis, Cornea, 2000;19:145-7.

26. LV H, Liu Z, Li X, Wang W, Effect of lacrimal plugs combined with deproteinized calf blood extract eye gel for filamentary keratitis, J Ocul Biol Dis Infor, 2010:3:134-40.
27. Gumus K, Lee S, Yen MT, Pflugfelder SC, Botulinum toxin injection for the management of refractory filamentary keratitis, Arch Ophthalmol, 2012:130:446-50.

28. Read SP, Rodriguez M, Dubovy S, et al., Treatment of Refractory Filamentary Keratitis With Autologous Serum Tears, Eye Contact Lens, 2015 [Epub ahead of print].

29. Holland EJ, Daya SM, Evangelista A, et al., Penetrating keratoplasty and transscleral fixation of posterior chamber lens, Am J Ophthalmol, 1992:114:182-7.

30. Olson RI, Complications associated with running 11-0 nylon suture in penetrating keratoplasty, Ophthalmic surg, 1982;13:558-61.

31. Shimazaki J, Shimmura S, Tsubota K, Intraoperative versus postoperative suture adjustment after penetrating keratoplasty, Cornea, 1998;17:590-4.

32. Forstot $S L$, Abel R, Jr, Binder PS, Bacterial endophthalmitis following suture removal after penetrating keratoplasty, $\mathrm{Am}$ । Ophthalmol, 1975:80(3 Pt 2):509-12.

33. Perry HD, Donnenfeld ED, Expulsive choroidal hemorrhag following suture removal after penetrating keratoplasty, Am J Ophthalmol, 1988;106:99-100.

34. Lam S, Tessler HH, Running nylon suture dissolution after penetrating keratoplasty, Am J Ophthalmol 1992:114:240-1.

35. Dana MR, Goren MB, Gomes JA, et al., Suture erosion after penetrating keratoplasty, Cornea, 1995:14:243-8.

36. Seitz B, El-Husseiny M, Langenbucher A, Szentmary N, Prophylaxis and management of complications in penetrating keratoplasty, Ophthalmologe, 2013;110:605-13

37. Holland EJ, Chan CC, Wetzig RP, et al., Clinical and immunohistologic studies of corneal rejection in the rat penetrating keratoplasty model, Cornea, 1991:10:374-80

38. Kostelna H, Rosocha J, Paulikova E, et al., Pathological findings in cornea tissue of patients with penetrating keratoplasty, Folia Histochem Cytobiol, 2010;48:267-72.

39. Pleskova AV, Khvatova AV, Postoperative complications of penetrating subtotal keratoplasty in children, Vestn Oftalmo 2002;118:14-17

40. Leahey AB, Avery RL, Gottsch JD, et al., Suture abscesses after penetrating keratoplasty, Cornea, 1993:12:489-92.

41. Sun YJ, Li AP, Pan ZQ, et al., Systematic review of penetrating keratoplasty rejection treated by immunosuppressants, Zhonghu Yan Ke Za Zhi, 2010;46:1122-7.

42. Birnbaum F, Maier P, Reinhard T, Intracameral application of corticosteroids for treating severe endothelial rejection after penetrating keratoplasty, Ophthalmologe, 2007;104:813-16.

43. Szaflik JP, Major J, Izdebska J, et al., Systemic immunosuppression with mycophenolate mofetil to prevent corneal graft rejection after high-risk penetrating keratoplasty: a 2-year follow-up study, Graefes Arch Clin Exp Ophthalmol, 2016:254:307-14.

44. Kaye DB, Epithelial response in penetrating keratoplasty, Am J Ophthalmol, 1980;89:381-7

45. Sharma A, Sharma S, Pandav SS, Mohan K, Post penetrating keratoplasty glaucoma: cumulative effect of quantifiable risk factors, Indian J Ophthalmol, 2014;62:590-5.

46. Lajmi H, El Afrit MA, Post-penetrating keratoplasty glaucoma management: report of 73 cases, J Fr Ophtalmol, 2014;37:220-5

47. Sandhu S, Petsoglou C, Grigg J, Veillard AS, Elevated Intraocular Pressure in Patients Undergoing Penetrating Keratoplasty and Descemet Stripping Endothelial Keratoplasty, J Glaucoma 2016:25:390-6.

48. Borderie VM, Loriaut P, Bouheraoua N, Nordmann JP, Incidence of Intraocular Pressure Elevation and Glaucoma after Lamella versus Full-Thickness Penetrating Keratoplasty, Ophthalmology, 2016:123:1428-34

49. Gupta P, Sharma A, Ichhpujani P, Post penetrating keratoplasty glaucoma - A review, Nepal J Ophthalmol, 2014;6:80-90.

50. Ward MS, Goins KM, Greiner MA, et al., Graft survival versus glaucoma treatment after penetrating or Descemet stripping automated endothelial keratoplasty, Cornea, 2014:33:785-9.

51. Starck T, Hopp L Held KS, et al, Low-dose intraocular tissue plasminogen activator treatment for traumatic total hyphema, postcataract, and penetrating keratoplasty fibrinous membranes, $J$ Cataract Refract Surg, 1995;21:219-24.

52. Snyder RW, Sherman MD, Allinson RW, Intracameral tissue plasminogen activator for treatment of excessive fibrin response after penetrating keratoplasty. Am J Ophthalmol, 1990;109:483-4.

53. Heidemann DG, Williams GA, Blumenkranz MS, Tissue plasminogen activator and penetrating keratoplasty, Ophthalmic Surg, 1990;21:364-5

54. Fukuda R, Usui T, Tomidokoro A, et al., Noninvasive observations of peripheral angle in eyes after penetrating keratoplasty using anterior segment fourier-domain optical coherence tomography, Cornea, 2012:31:259-63.

55. Yenerel NM, Kucumen RB, Gorgun E, The complementary benefit of anterior segment optical coherence tomography in penetrating keratoplasty, Clin Ophthalmol, 2013;7:1515-23.

56. Karadag O, Kugu S, Erdogan G, et al., Incidence of and risk factors for increased intraocular pressure after penetrating keratoplasty, Cornea, 2010:29:278-82

57. Inoue K, Amano S, Oshika T, Tsuru T, Risk factors for corneal graft failure and rejection in penetrating keratoplasty, Acta Ophthalmol Scand, 2001;79:251-5.

58. Greenlee EC, Kwon YH, Graft failure: III. Glaucoma escalation after penetrating keratoplasty, Int Ophthalmol, 2008;28:191-207.

59. Memarzadeh F LiY, Francis BA, et al, Optical coherence tomography of the anterior segment in secondary glaucoma with corneal opacity after penetrating keratoplasty, Br $\perp$ Ophthalmol, 2007:91:189-92

60. Sternberg P Jr, Meredith TA, Stewart MA, Kaplan HJ, Retina detachment in penetrating keratoplasty patients, $\mathrm{Am}$ 」 Ophthalmol, 1990:109:148-52.

61. Park Y, Kim MH, Won JY, et al., Vitreoretinal Complications after Penetrating Keratoplasty. Retina 2016; doi: 10.1097/ IAE.0000000000001049.

62. Duncker Gl, Rochels R, Delayed suprachoroidal hemorrhage after penetrating keratoplasty, Int Ophthalmol, 1995;19:173-6.

63. Sung MS, Choi W, You IC, Yoon KC, Factors Affecting Treatment Outcome of Graft Infection Following Penetrating Keratoplasty, Korean I Ophthalmol, 2015;29:301-8.

64. Shi W, Liu M, Gao H, et al., Perioperative treatment and prognostic factors for penetrating keratoplasty in Acanthamoeba keratitis unresponsive to medical treatment, Graefes Arch Clin Exp Ophthalmol, 2009:247:1383-8.

65. Wagoner MD, Al-Swailem SA, Sutphin JE, Zimmerman MB, Bacterial keratitis after penetrating keratoplasty: incidence, microbiological profile, graft survival, and visual outcome, Ophthalmology, 2007;114:1073-9.

66. Constantinou M, Jhanji V, Vajpayee RB, Clinical and microbiologica profile of post-penetrating keratoplasty infectious keratitis in failed and clear grafts, Am J Ophthalmol, 2013:155:233-7 e232.

67. Smith SD, Clinical and microbiological profile of post-penetrating keratoplasty infectious keratitis in failed and clear grafts, Am J Ophthalmol, 2013;156:626

68. Yang JW, Lin $\mathrm{HC}$, Hsiao $\mathrm{CH}$, Chen PY, Therapeutic penetrating keratoplasty in severe infective keratitis using glycerol-preserved donor corneas, Cornea, 2012:31:1103-6.

69. Iverson SM, Spierer O, Papachristou GC, et al., Comparison of primary graft survival following penetrating keratoplasty and Descemet's stripping endothelial keratoplasty in eyes with prio trabeculectomy, Br J Ophthalmol, 2015:99:1477-82.

70. Patel SV, Diehl NN, Hodge DO, Bourne WM, Donor risk factors fo graft failure in a 20-year study of penetrating keratoplasty, Arch Ophthalmol, 2010;128:418-25.

71. Wagoner MD, Ba-Abbad R, Al-Mohaimeed M, et al., Postoperative complications after primary adult optical penetrating keratoplasty: prevalence and impact on graft survival, Cornea, 2009;28:385-94.

72. Sugar A, Gal RL, Kollman C, et al., Factors associated with corneal graft survival in the cornea donor study, JAMA Ophthalmol 2015:133:246-54.

73. Wakefield MJ, Armitage WJ, Jones MN, et al., The impact of donor age and endothelial cell density on graft survival following penetrating keratoplasty, Br J Ophthalmol, 2016;100:986-9.

74. Lass JH, Sugar A, Benetz BA, et al., Endothelial cell density to predict endothelial graft failure after penetrating keratoplasty، Arch Ophthalmol, 2010;128:63-9.

75. Weisbrod DJ, Sit M, Naor J, Slomovic AR, Outcomes of repeat penetrating keratoplasty and risk factors for graft failure, Cornea, 2003;22:429-34 